\title{
TITLE:
}

\section{Characterization of wood-based molding bonded with citric acid}

$\operatorname{AUTHOR}(S)$ :

Umemura, Kenji; Ueda, Tomohide; Kawai, Shuichi

\section{CITATION:}

Umemura, Kenji ... [et al]. Characterization of wood-based molding bonded with citric acid. Journal of Wood Science 2012, 58(1): 38-45

\section{ISSUE DATE:}

2012-02

URL:

http://hdl.handle.net/2433/154635

\section{RIGHT:}

The final publication is available at www.springerlink.com; This is not the published version. Please cite only the published version.; この論文 は出版社版でありません。引用の際には出版社版をご確認ご利用くだ さい。 


\title{
Characterization of Wood-based Molding Bonded with Citric Acid.
}

\author{
Kenji Umemura $^{a^{*}}$, Tomohide Ueda ${ }^{b}$, Shuichi Kawai ${ }^{a}$
}

${ }^{a}$ Research Institute for Sustainable Humanosphere, Kyoto University, Gokasho Uji, Kyoto 611-0011, Japan

${ }^{\mathrm{b}}$ Eidai Co., Ltd., Eidai cho, Tsuruga, Fukui 914-0825, Japan

*Corresponding author. Tel: +81-774-38-3652; Fax: +81-774-38-3678.

E-mail address: umemura@rish.kyoto-u.ac.jp 


\begin{abstract}
:
The wood-based moldings were fabricated by using only citric acid as an adhesive. The mechanical properties, water resistances, thermal properties and chemical structure were investigated. Wood powder obtained from Acacia mangium was mixed with citric acid under certain weight ratios $(0-40 \mathrm{wt} \%)$, and each powder mixture was molded using two types of metal molds at $200{ }^{\circ} \mathrm{C}$ and $4 \mathrm{MPa}$ for $10 \mathrm{~min}$. The modulus of rupture (MOR) and the modulus of elasticity (MOE) values of the wood-based molding containing $20 \mathrm{wt} \%$ citric acid were 35.8 $\mathrm{MPa}$ and $5.4 \mathrm{GPa}$, respectively. The maximum impact strength was $0.94 \mathrm{~kJ} / \mathrm{m}^{2}$ with the same citric acid content. The water resistance increased with increasing citric acid content, and the good resistance to boiling water was also recognized. However, some elution of substances derived from citric acid was observed at high levels of citric acid, causing a decrease in the thermal properties. The ester linkages were detected by Fourier transform infrared spectroscopy (FT-IR), indicating that the citric acid reacted with the wood. Our results demonstrated that citric acid brings about good adhesiveness for fabricating the wood-based molding.
\end{abstract}

Keywords:

Wood-based molding, Citric acid, Natural wood adhesive, Physical properties 


\section{Introduction}

The demand for sustainable wood-based materials is expected to continue to increase. At present, synthetic resin adhesives derived from fossil resources are required when manufacturing wood-based materials. Considering the concerns about the future global environment and the potential shortage of resources, it is desirable to reduce the consumption of synthetic resin adhesives. Recently, studies on natural adhesives using bio-resources have been performed with protein, tannin and lignin used as the main adhesive materials. ${ }^{1}$ However, when synthesizing these natural adhesives, chemical agents derived from fossil resources that cause health disorders and environmental problems are commonly necessary. In the further development of natural adhesives, the use of chemical agents should be restrained as much as possible.

In our previous research, we were able to make bark molding using only citric acid as an adhesive. ${ }^{2}$ The molding had good mechanical properties and water resistance. Citric acid (2-hydroxy-1,2,3-propanetricarboxylic acid) is an organic polycarboxylic acid containing three carboxyl groups. It is contained in citrus fruits such as lemons and limes and is commercially produced by fermentation of glucose or glucose- and sucrose- containing materials. ${ }^{3,4}$ It is widely used in food, beverages and pharmaceuticals. In addition, citric acid has been researched as a cross-linking agent for wood ${ }^{5}$, plant fiber ${ }^{6}$, paper ${ }^{7}$, starch $^{8}$ and bio-based elastomers. ${ }^{9}$ In this study, wood-based molding was fabricated to clarify the possibility of using citric acid as a wood adhesive. The effects of citric acid content on the physical and chemical properties of the molding were investigated.

\section{Materials and methods}

\subsection{Materials}

A wood block of Acacia mangium obtained from a Japanese wood company was pulverized, and wood powder was obtained by using a sieve of $250 \mu \mathrm{m}$ mesh size. Citric acid was purchased from Nacalai Tesque, Inc., and was also pulverized into less than $250 \mu \mathrm{m}$ mesh size. These materials were vacuum-dried at $60^{\circ} \mathrm{C}$ for $15 \mathrm{~h}$.

\subsection{Molding preparation}

The citric acid powder was put into a plastic cup with the wood powder. The citric acid contents (wt\%) were adjusted to $0,11.1,20.0,33.3$ and 40.0, giving weight ratios of wood / citric acid of 10:0, 8:1, 4:1, 2:1 and 1.5:1, respectively. Details regarding the formulations are shown in Table 1. The top of the cup was covered with aluminum foil, and the cup was shaken 
vigorously by hand for a few seconds. A cylindrical mold with a $70 \mathrm{~mm}$ inner diameter and a dumbbell-shaped mold of the Japanese Industrial Standard (JIS) K 7139-1966 A type were used for making molding. The mixture powder was poured into the molds and hot-pressed at $200^{\circ} \mathrm{C}$ and $4 \mathrm{MPa}$ for $10 \mathrm{~min}$. The moldings obtained were stored in a desiccator with silica gel.

\subsection{Bending test}

Both edges of the dumbbell-shaped molding were cut, and rectangular specimens of $80 \times 10 \times 4-6 \mathrm{~mm}$ were prepared. The static 3 -point bending test was carried out under $50 \mathrm{~mm}$ of span and $5 \mathrm{~mm} / \mathrm{min}$ of loading speed. The test was performed in triplicate, and each average value with standard deviation of the modulus of rupture (MOR) and the modulus of elasticity (MOE) was calculated.

\subsection{Charpy impact test}

According to JIS K 7111, the Charpy impact test was carried out using a digital impact tester DG-CD (Toyo Seiki Seisaku-sho, Ltd.). A rectangular of $80 \times 10 \times 4-6 \mathrm{~mm}$ specimen was prepared, and the impact strength in the flatwise direction was measured with 5 unnotched sample replicates. The average value with standard deviation was calculated.

\subsection{Water immersion treatment}

Water immersion treatment was performed at $20^{\circ} \mathrm{C}$ for $24 \mathrm{~h}$ using three rectangular specimens $(50 \times 20 \mathrm{~mm})$ cut from the circular molding. After the treatment, thickness swelling (TS), linear expansion (LE) and weight increase were measured under wet condition. The wet specimens were then vacuum-dried at $60^{\circ} \mathrm{C}$ for $15 \mathrm{hr}$, and the weight change based on the weight before treatment was calculated.

\subsection{Repeated boiling treatment}

The weight and thickness changes caused by a repeated boiling treatment were observed using the edge (about $20 \times 20 \mathrm{~mm}$ ) of the dumbbell-shaped molding. The treatment condition was boiling water immersion for $4 \mathrm{~h}$, drying at $60^{\circ} \mathrm{C}$ for $20 \mathrm{~h}$ in an oven, boiling water immersion for $4 \mathrm{~h}$ and vacuum-drying at $60^{\circ} \mathrm{C}$ for $15 \mathrm{~h}$. The experiment was performed triplicate, and average value with standard deviations was calculated.

\subsection{Thermal analysis}


The molding obtained was pulverized into less than $150 \mu \mathrm{m}$ mesh size, and the powder was vacuum-dried at $60^{\circ} \mathrm{C}$ for $15 \mathrm{~h}$. The thermogravimetric analysis (TGA) was carried out using a TGA 2050 (TA Instruments Japan). The powder was scanned from room temperature to $550^{\circ} \mathrm{C}$ at a rate of $10^{\circ} \mathrm{C} / \mathrm{min}$ under nitrogen purging. The differential scanning calorimetry (DSC) measurement was conducted using a DSC 2910 (TA Instruments Japan). The powder was encapsulated in an aluminum pan and scanned from room temperature to $350^{\circ} \mathrm{C}$ at a rate of $10^{\circ} \mathrm{C} /$ min under nitrogen purging.

\subsection{Fourier transform infrared spectroscopy (FT-IR)}

All of the infrared spectra were obtained with an Fourier transform infrared spectrophotometer (FT/IR-4200, JASCO Corporation) by using the KBr disk method and were recorded by means of an average of 16 scans at a resolution of $4 \mathrm{~cm}^{-1}$.

\section{Results and discussion}

\subsection{Mechanical properties.}

When the mixture of wood and citric acid powders was molded, rigid molding was obtained. Table 2 shows the density of the molding specimen used for the bending test. The molding density ranged from 0.75 to $1.21 \mathrm{~g} / \mathrm{cm}^{3}$, and the density increased with increasing citric acid content. Fig. 1 shows the effects of citric acid content on the bending properties. The average MOR and MOE values of the wood-only molding ( $0 \mathrm{wt} \%$ ) were $1.2 \mathrm{MPa}$ and $0.27 \mathrm{GPa}$, respectively. This indicated that the molding made of only wood powder developed almost no bending properties. The bending properties were increased drastically by the addition of citric acid. The maximum average MOR value was $35.8 \mathrm{MPa}$ with a $20.0 \mathrm{wt} \%$ citric acid content, and the specific MOR considering the density was $30.4 \mathrm{MPa}$. The maximum average MOE value was $5.9 \mathrm{GPa}$ with a $33.3 \mathrm{wt} \%$ citric acid content, and the specific MOE was $4.9 \mathrm{GPa}$. The citric acid content of $40.0 \mathrm{wt} \%$ brought a decrease in the bending properties due to the excess citric acid in the molding. Compared to the results obtained with molding composed of Acacia mangium bark and citric acid in our previous paper, ${ }^{2}$ high bending properties were recognized. Fig. 2 shows the effect of citric acid content on the impact strength. The maximum average value was $0.94 \mathrm{~kJ} / \mathrm{m}^{2}$ with a $20.0 \mathrm{wt} \%$ citric acid content, which was about three times higher than the value of the wood-only molding. A further addition of citric acid did not contribute to the enhancement of the strength. Based on the results shown in Figs. 1 and 2, the optimum citric acid content for the mechanical properties was $20.0 \mathrm{wt} \%$. 


\subsection{Water resistance}

Fig. 3 shows the relationship between the molding weight and citric acid content in the water immersion treatment. The weight increase in the wood-only molding ( $0 \mathrm{wt} \%)$ exceeded $100 \%$, and the weight change after drying was about $-2.3 \%$. This indicated that absorption and desorption of water mainly occurred during treatment. In the case of the molding with citric acid, the weight increase was inhibited as the citric acid content increased. However, the weight change after drying decreased in opposition to the increasing citric acid content, and the value of the molding with $40.0 \mathrm{wt} \%$ citric acid content was $-32.1 \%$. Judging from the behavior of the wood-only molding, substances related to citric acid would be eluted. Fig. 4 shows the dimensional stabilities of the molding in water immersion treatment. In the case of the wood-only molding, both the TS and LE exhibited high values. When citric acid was added, the dimensional stabilities of the molding were improved drastically. Compared to the values of the wood-only molding, the values of the molding with $11.1 \mathrm{wt} \%$ citric acid content were less than one third as much. The values of TS and LE were less than $10 \%$ and $1 \%$ as much, respectively, in samples with $20.0 \mathrm{wt} \%$ citric acid content and more.

To further clarify the effect of citric acid content on water resistance of the molding, a repeated boiling treatment was performed. Fig. 5 shows the effect of citric acid content on the weight change in the treatment. The wood-only molding decomposed completely during the first boiling treatment, while the form of the molding containing citric acid was maintained, irrespective of the amount of citric acid added during the treatment. The weight increase of the molding in the first boiling treatment was inhibited with increasing citric acid content. A marked effect was observed in samples of $20.0 \mathrm{wt} \%$ or more. Weight decreases ranging from -7.6 to $-42.6 \%$ were observed after the first drying treatment, indicating that some elution from the molding occurred during the first boiling treatment. The range of weight decrease in the second drying treatment following the second boiling treatment was -14.3 to $-54.2 \%$. Fig.6 shows the thickness changes in the treatment. The measurement of the molding with $40.0 \mathrm{wt} \%$ citric acid content was difficult because of marked deformation. In the case of molding with $11.1 \mathrm{wt} \%$ citric acid content, the thickness change after the first boiling treatment was $65.1 \%$ and the value following the second treatment was $72.9 \%$. The final dried thickness change after the treatment was 52.6\%. Though the molding kept its form even after the treatment, a remarkable increase of the thickness was observed. The thickness change of the molding with $20.0 \mathrm{wt} \%$ citric acid was greatly suppressed, and the final dried thickness change was $6.2 \%$. The molding with $33.3 \mathrm{wt} \%$ citric acid became even smaller. Based on the results of Figs. 3 to 6 , 
it was clarified that the molding with citric acid had water resistance. In particular, the molding with $20.0 \mathrm{wt} \%$ citric acid content had excellent properties.

\subsection{Thermal properties of the molding.}

Fig. 7 shows the thermogravimetric (TG) and derivative TG (DTG) curves of the moldings. The pure citric acid measured as a reference had one-stage degradation in the temperature range of 150 to $250^{\circ} \mathrm{C}$. Citric acid melts at $153^{\circ} \mathrm{C}$ and dehydrates to give aconitic acid on heating at $175^{\circ} \mathrm{C}^{10}$ In the DTG curve, the wood-only molding $(0 \mathrm{wt} \%)$ exhibited two-step degradation. The first stage was observed at around $270^{\circ} \mathrm{C}$ as a shoulder, and can be attributed to the decomposition of hemicellulose and the slower decomposition of lignin. The second stage was at around $350^{\circ} \mathrm{C}$, and can be attributed to the decomposition of cellulose. ${ }^{11}$ The shoulder at around $270^{\circ} \mathrm{C}$ decreased with increasing citric acid content, indicating the change of the hemicellulose and lignin components. The second peak at around $350^{\circ} \mathrm{C}$ was observed irrespective of citric acid content. Another peak appeared clearly at around $200^{\circ} \mathrm{C}$ with increasing citric acid content. Considering the weight loss behavior of pure citric acid, this peak seemed to be caused by substances derived from citric acid. The TG of the molding excluding the effect of substances derived from citric acid was investigated using the molding after a repeated boiling treatment. The results are shown in Fig.8. According to the DTG, the peak at around $200^{\circ} \mathrm{C}$ was not observed, indicating that the substances were completely removed in the treatment. The small shoulder at around $270^{\circ} \mathrm{C}$ was only observed in 11.1 and $20.0 \mathrm{wt} \%$ citric acid. The maximum peak at around $350^{\circ} \mathrm{C}$ was observed in all moldings as it was in the molding without treatment.

Fig. 9 shows DSC curves of the moldings. Citric acid had a sharp endotherm at $157^{\circ} \mathrm{C}$ and a broad endotherm at around $220^{\circ} \mathrm{C}$, indicating melting and decomposition, respectively. ${ }^{10}$ In the wood-only molding, a broad endotherm was observed at around $130^{\circ} \mathrm{C}$. The weight change was scarcely recognized at that temperature, as shown in Fig.7. Therefore, the endotherm was due to the weakening of the hydrogen bonds between carbohydrates. ${ }^{12}$ The curve change at above $250^{\circ} \mathrm{C}$ was attributed to a marked degradation of wood. ${ }^{13,14}$ In the case of molding with citric acid, the endotherm at around $130^{\circ} \mathrm{C}$ disappeared gradually with increasing citric acid content, indicating effect of substances derived from citric acid. The endotherm at around $157^{\circ} \mathrm{C}$ derived from citric acid was not observed, even when the citric acid content was $40.0 \mathrm{wt} \%$, probably because of a chemical change in the citric acid during molding. The endotherm at around $210^{\circ} \mathrm{C}$ gradually appeared. Judging from the results shown in Fig.7, this would have been due to the decomposition of substances derived from citric acid. Fig.10 shows DSC curves of the molding 
after a repeated boiling treatment. The endotherm at around $120^{\circ} \mathrm{C}$ was observed irrespective of citric acid content. However, the peak tended to become small with increasing citric acid content. Based on the results shown in Figs.8 and 9, the endotherm resulted from the weakening of the hydrogen bonds. The broad endotherm between 200 to $300^{\circ} \mathrm{C}$ was also observed irrespective of citric acid content. This was probably derived from the degradation of the molding, but a marked difference was scarcely recognized.

\subsection{Chemical structure of the molding.}

The effect of citric acid content on the chemical structure of the molding was investigated by FT-IR, and the results are shown in Fig.11. The absorption bands at around 2628, 1733 and $1209 \mathrm{~cm}^{-1}$ increased as citric acid content increased. The broad absorption band at around 2628 $\mathrm{cm}^{-1}$ was ascribed to the vibration of $\mathrm{H}$-bonded carboxylic $\mathrm{OH}$ groups. ${ }^{15}$ The peak at around $1733 \mathrm{~cm}^{-1}$ was attributed to $\mathrm{C}=\mathrm{O}$ stretching derived from the carboxyl group and/or $\mathrm{C}=\mathrm{O}$ ester group. ${ }^{15,16}$ The peak at around $1209 \mathrm{~cm}^{-1}$ was attributed to $\mathrm{C}-\mathrm{O}$ stretching and $-\mathrm{OH}$ bending motions. ${ }^{17,18}$ The peaks derived from citric acid appeared strongly when the citric acid content was high. According to the results shown in Figs. 3 and 5, the moldings contained some water-soluble substances. To observe the chemical structure of the molding that excluded the water-soluble substances, FT-IR measurements were taken of the moldings after a repeated boiling treatment. The results are shown in Fig.12. The result of the wood-only molding was not obtained because of decomposition in the treatment. The absorption bands at around 2628 and $1209 \mathrm{~cm}^{-1}$ were hardly recognized in any moldings. The absorption band at around $1733 \mathrm{~cm}^{-1}$ increased a little as citric acid content increased, implying that the ester linkages increased. Therefore, citric acid reacted with wood, and as a result, moldings with good physical properties were fabricated.

\section{Conclusions}

The physical and chemical properties of molding composed of wood powder and citric acid were investigated. The molding had good bending properties and impact strength. In particular, the molding with $20.0 \mathrm{wt} \%$ citric acid content showed excellent values. The water resistance increased with increasing citric acid content, and good resistance against boiling water was also recognized. However, marked elution caused by substances derived from citric acid was observed in samples with high citric acid content. The thermal properties of the molding decreased with increasing citric acid content. However, a significant difference of the thermal properties was scarcely observed in the moldings after a repeated boiling treatment, irrespective 
of citric acid content. Based on the results of FT-IR, it was clarified that the bonding mechanism of the molding was ester linkages between wood and citric acid. We therefore concluded that citric acid can be used as an adhesive for wood-based molding.

\section{Acknowledgments}

This work was financially supported by Grant-in-Aid for Scientific Research (C) (No.21580206) from the Ministry of Education, Culture, Sports, Science and Technology, Japan, and Special Coordination Funds for Promoting Science and Technology entitled "Creation of the paradigm of sustainable use of tropical rainforest by the intensive forest management and advanced utilization of forest resources".

\section{REFERENCES}

1. Pizzi A (2006) Recent development in eco-efficient bio-based adhesives for wood bonding: opportunities and issues. J Adhesion Sci Technol 20: 829-846

2. Umemura K, Ueda T, Sasa S M, Kawai S (2011) Application of citric acid as natural adhesive for wood. J Appl Polym Sci (Accepted)

3. Abou-Zeid, A-ZA, Ashy MA (1984) Production of citric acid: A Review. Agricultural wastes 9: $51-76$

4. Tsao GT, Cao NJ, Du J, Gong CS (1999) Production of multifunctional organic acids from renewable resources. Adv Biochem Eng Biotechnol 65: 243-278

5. Vukusic SB, Katovic D, Schramm C, Trajkovic J, Sefc B (2006) Polycarboxylic acids as non-formaldehyde anti-swelling agents for wood. Holzforschung 60: 439-444.

6. Ghosh P, Das D, Samanta AK (1995) Modification of jute with citric acid. J Polym Mater 12: 297-305

7. Yang CQ, Xu Y, Wang D (1996) FT-IR spectroscopy study of the polycarboxylic acids used for paper wet strength improvement. Ind Eng Chem Res 35: 4037-4042

8. Reddy N, Yang Y (2010) Citric acid cross-linking of starch films. Food Chemi 118: 702-711

9. Tran, RT, Zhang Y, Gyawali D, Yang J (2009) Recent development on citric acid derived biodegradable elastomers. Recent plants on biomedical engineering 2: 216-227

10. Barbooti MM, Al-Sammerrai DA (1986) Thermal decomposition of citric acid. Thermochim Acta 98: 119-126

11. Shebani AN, Reenen AJ, Meincken M (2008) The effect of wood extractives on the thermal stability of different wood species. Thermochimi Acta 471: 43-50 
12. Mehrotra R, Singh P, Kandpal H (2010) Near infrared spectroscopic investigation of the thermal degradation of wood. Thermochimi Acta 507-508: 60-65

13. Beall FC (1971) Differential calometric analysis of wood and wood components. Wood Sci Technol 5: 159-175

14. Tsujuyama S, Miyamori A (2000) Assignment of DSC thermograms of wood and its components. Thermochimi Acta 351: 177-181

15. Žagar E, Grdadolnik J (2003) An infrared spectroscopic study of H-bond network in hyperbranched polyester polyol. J Mol Struct 658: 143-152

16. Yang CQ, Wang X (1996) Formation of cyclic anhydride intermediates and esterification of cotton cellulose by multifunctional carboxylic acids: An infrared spectroscopy study. Tex Res J 66: 595-603

17. Lackovic K, Johnson BB, Angove MJ, Wells JD (2003) Modeling the adsorption of citric acid onto Muloorina illite and related clay minerals. J Colloid Interface Sci 267: 49-59

18. Schwanninger M, Rodrigues JC, Pereira H, Hinterstoisser B (2004) Effects of short-time vibratory ball mill on the shape of FT-IR spectra of wood and cellulose. Vibrational Spectroscopy 36: 23-40

Figure \& Table Captions

Fig.1. Bending properties of the moldings.

Fig.2. Impact strength of the moldings.

Fig.3. Weight change of the moldings in water immersion treatment for $24 \mathrm{~h}$.

Fig.4. Dimensional stabilities of the moldings in water immersion treatment for $24 \mathrm{~h}$.

Fig.5. Weight changes of the moldings in a repeated boiling treatment.

Fig.6. Thickness changes of the moldings in a repeated boiling treatment.

Fig.7. TG and DTG curves of the moldings.

Fig.8.TG and DTG curves of the moldings after a repeated boiling treatment.

Fig.9. DSC curves of the moldings.

Fig.10. DSC curves of the moldings after a repeated boiling treatment.

Fig.11. Infrared spectra of the moldings.

Fig.12. Infrared spectra of the moldings after a repeated boiling treatment.

Table 1. Formulation of the moldings. 
Table 2. Densitiy of the specimens for bending test. 
Table 1. Formulation of the moldings.

\begin{tabular}{c|c|cc|cc}
\hline \multirow{2}{*}{$\begin{array}{c}\text { Citric acid content } \\
(\text { wt\% })\end{array}$} & $\begin{array}{c}\text { Weight ratio of } \\
\text { citric acid to } \\
\text { wood }\end{array}$ & Mold for JIS K 7139 & \multicolumn{2}{|c}{ Cylindrical mold } \\
\cline { 3 - 5 } & $10: 0$ & 10.00 & 0.00 & Wood $(\mathrm{g})$ & $\begin{array}{c}\text { Citric acid } \\
(\mathrm{g})\end{array}$ \\
\hline 0.0 & $8: 1$ & 8.89 & 1.11 & & 0.00 \\
11.1 & $4: 1$ & 8.00 & 2.00 & 10.00 & 2.50 \\
20.0 & $2: 1$ & 6.67 & 3.33 & & 5.00 \\
33.3 & $1.5: 1$ & 6.00 & 4.00 & & 6.67 \\
40.0 & & & & & \\
\hline
\end{tabular}

Table 2. Densitiy of the specimens for bending test.

\begin{tabular}{cccccc}
\hline $\begin{array}{c}\text { Citric acid content } \\
(\mathrm{wt} \%)\end{array}$ & 0 & 11.1 & 20 & 33.3 & 40 \\
\hline Density $\left(\mathrm{g} / \mathrm{cm}^{3}\right)$ & 0.75 & 0.91 & 1.18 & 1.21 & 1.21 \\
\hline Standard deviation & 0.004 & 0.009 & 0.02 & 0.019 & 0.015 \\
\hline
\end{tabular}




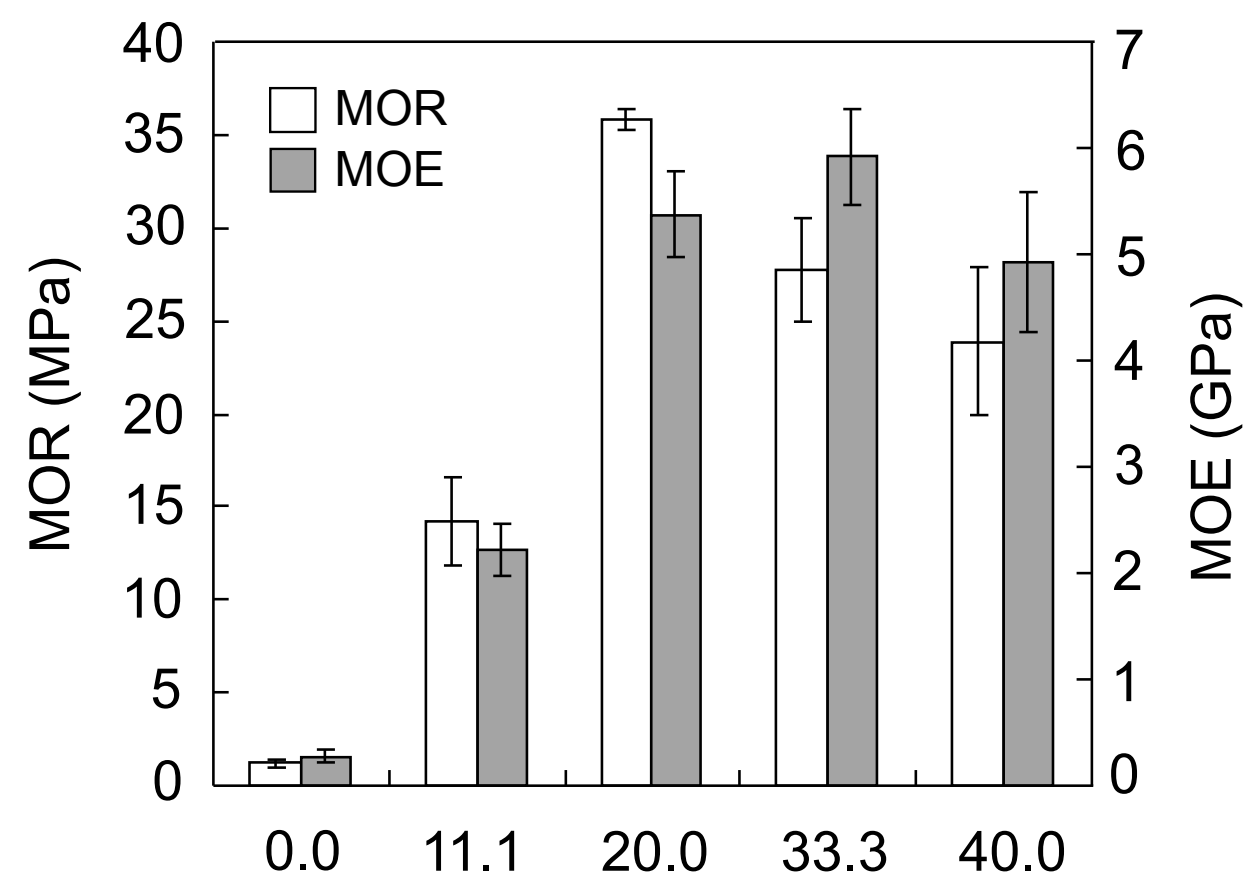

Citric acid content (wt\%)

Fig. 1. 


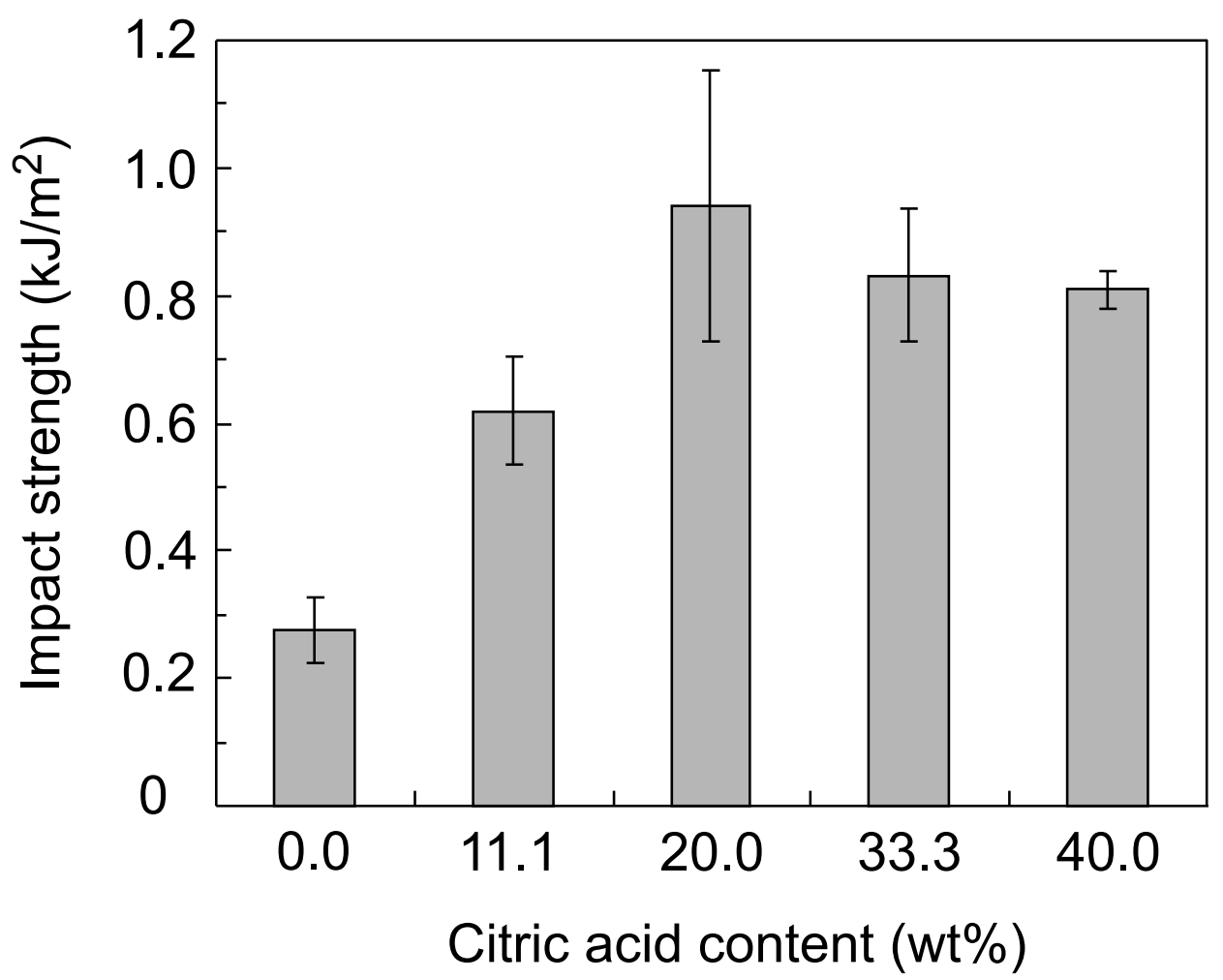

Fig. 2. 


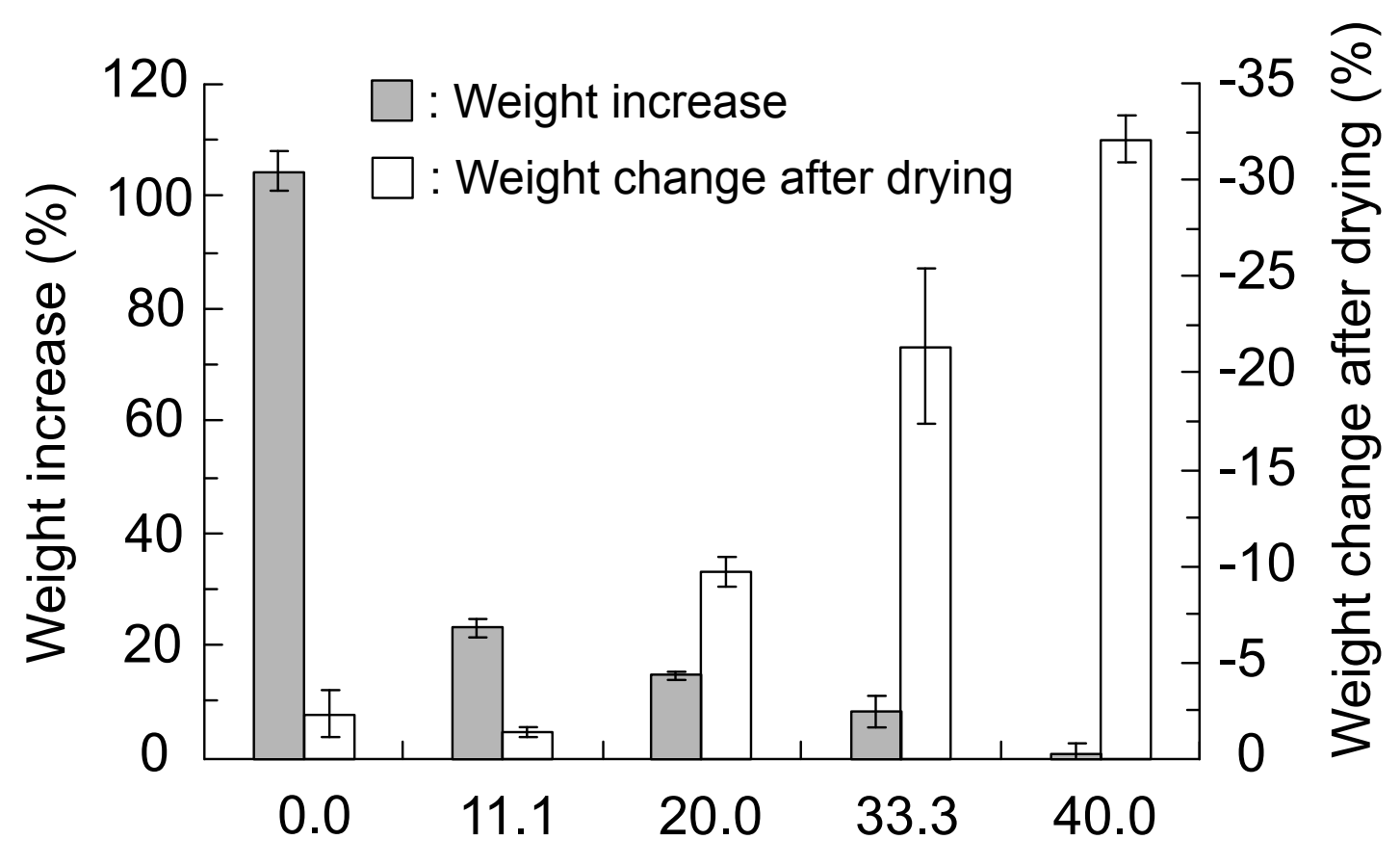

Citric acid content (wt\%)

Fig. 3. 


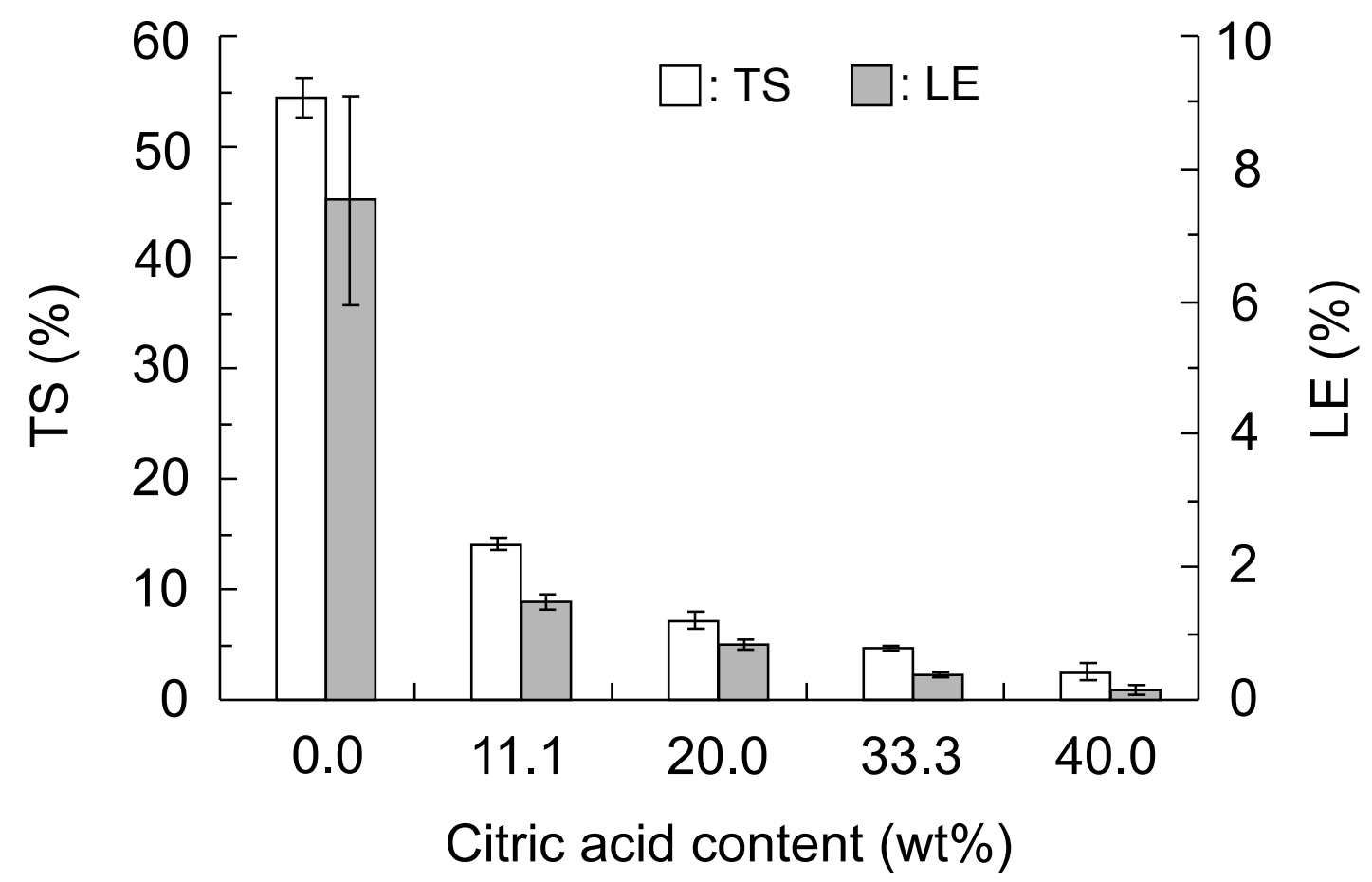

Fig. 4. 


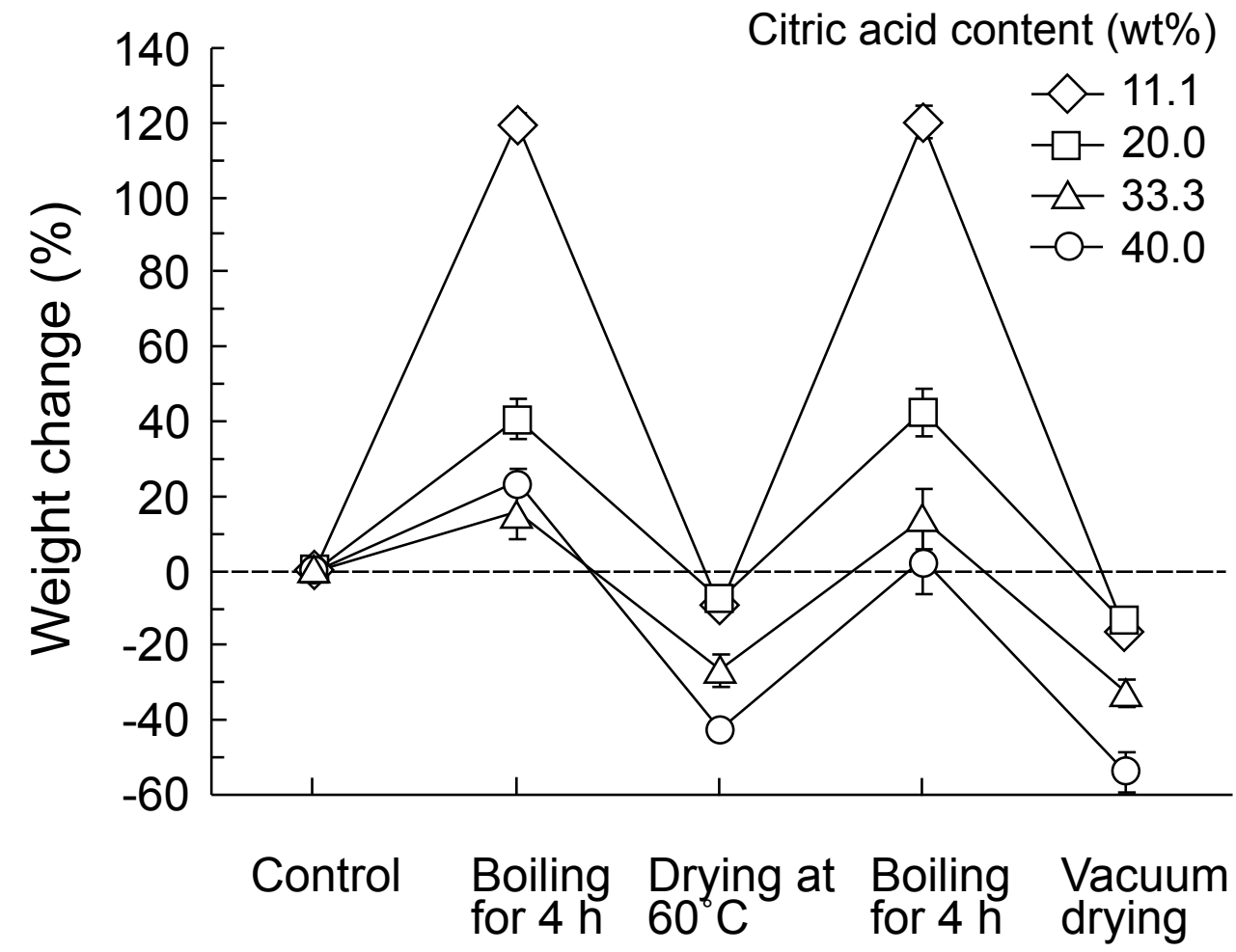

Fig. 5. 


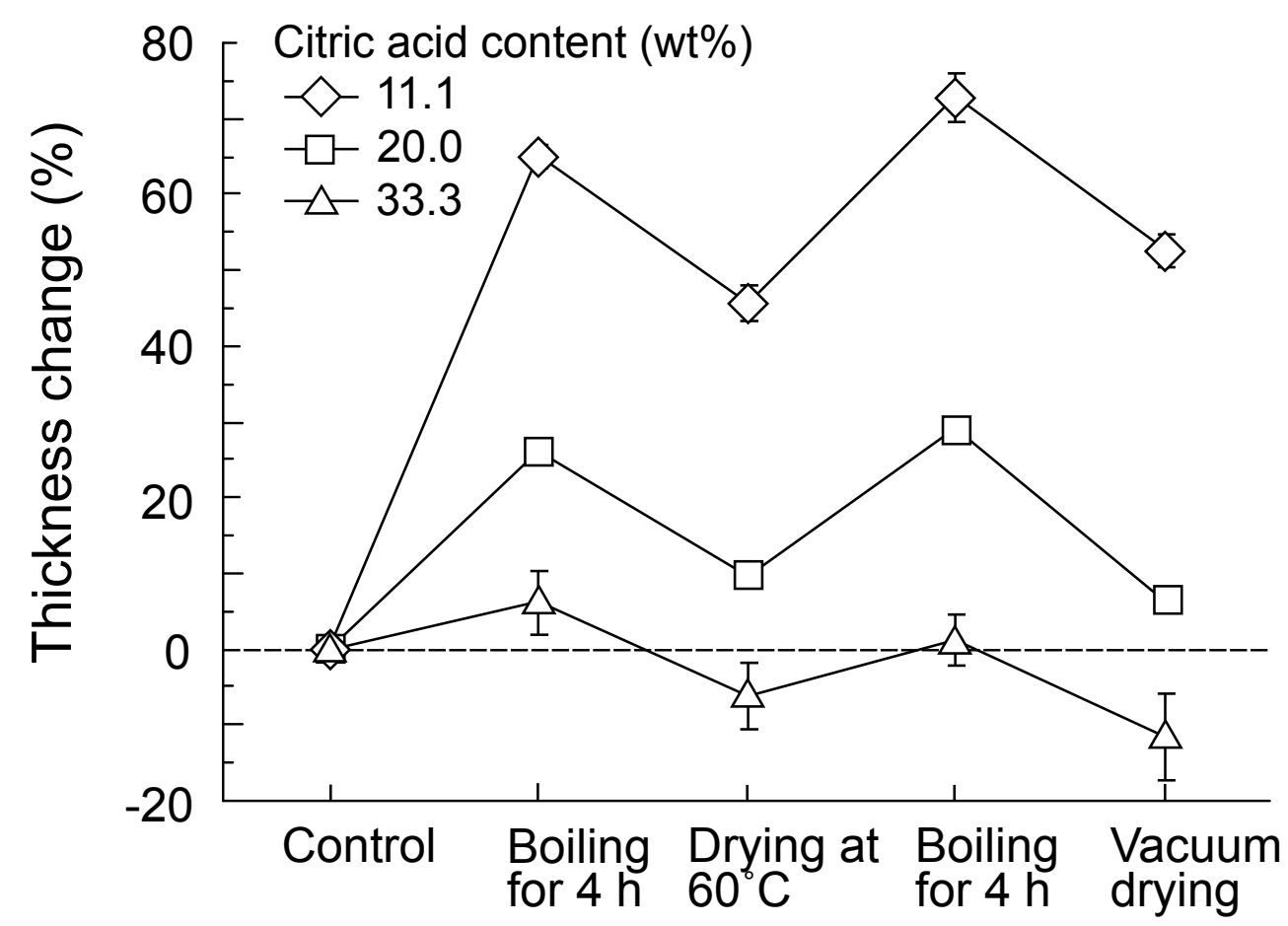

Fig. 6. 

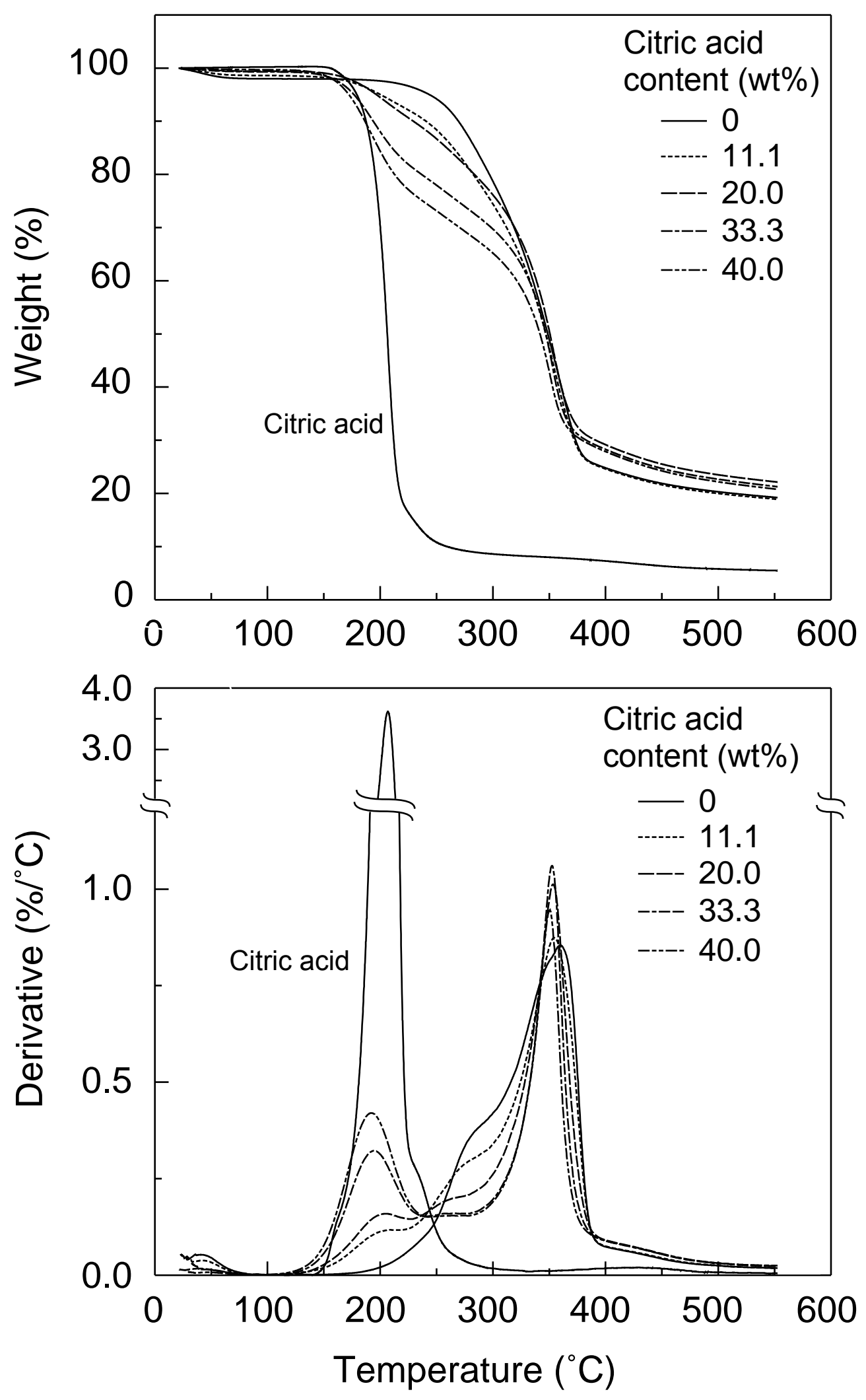

Fig. 7. 

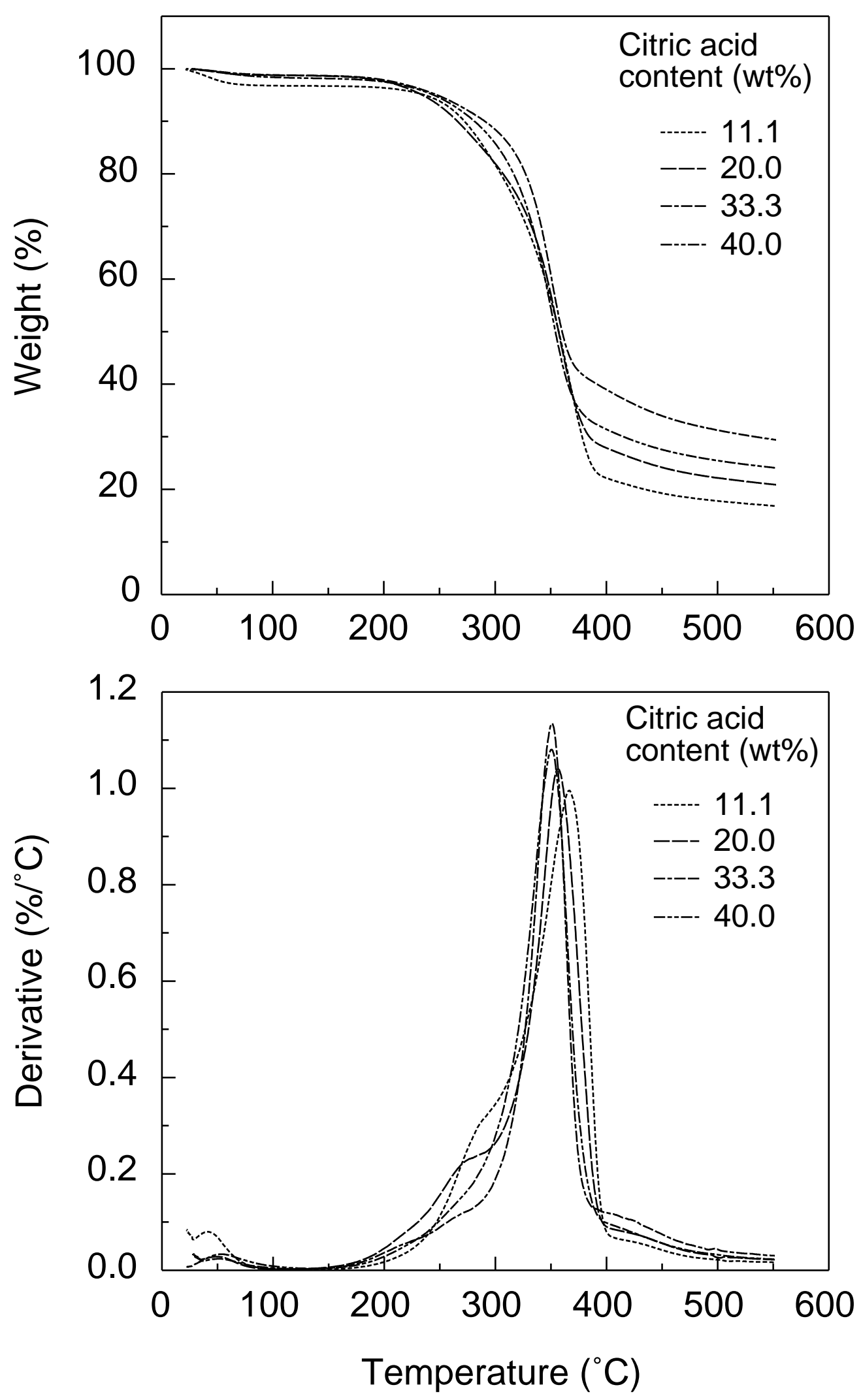

Fig. 8. 


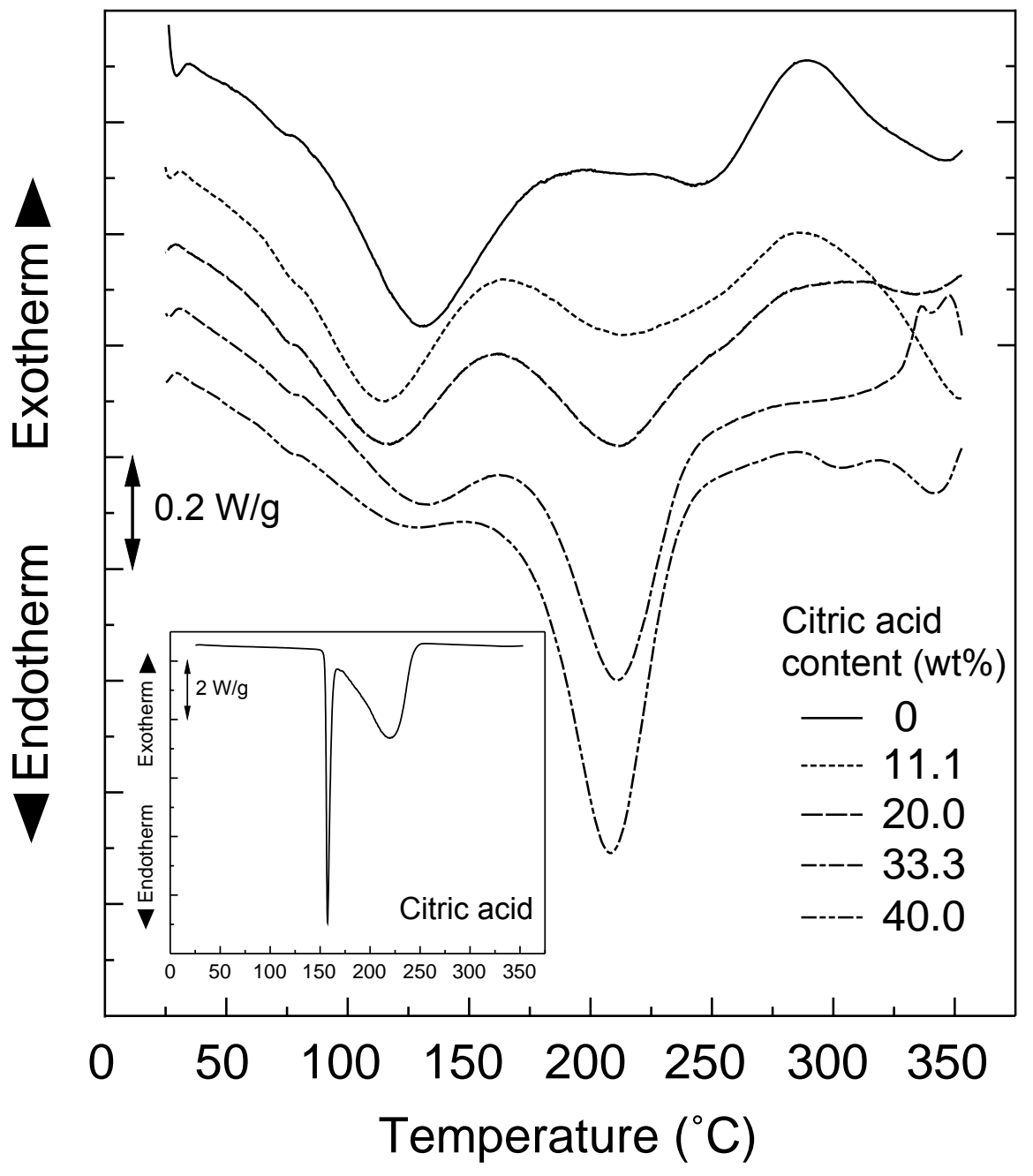

Fig. 9. 


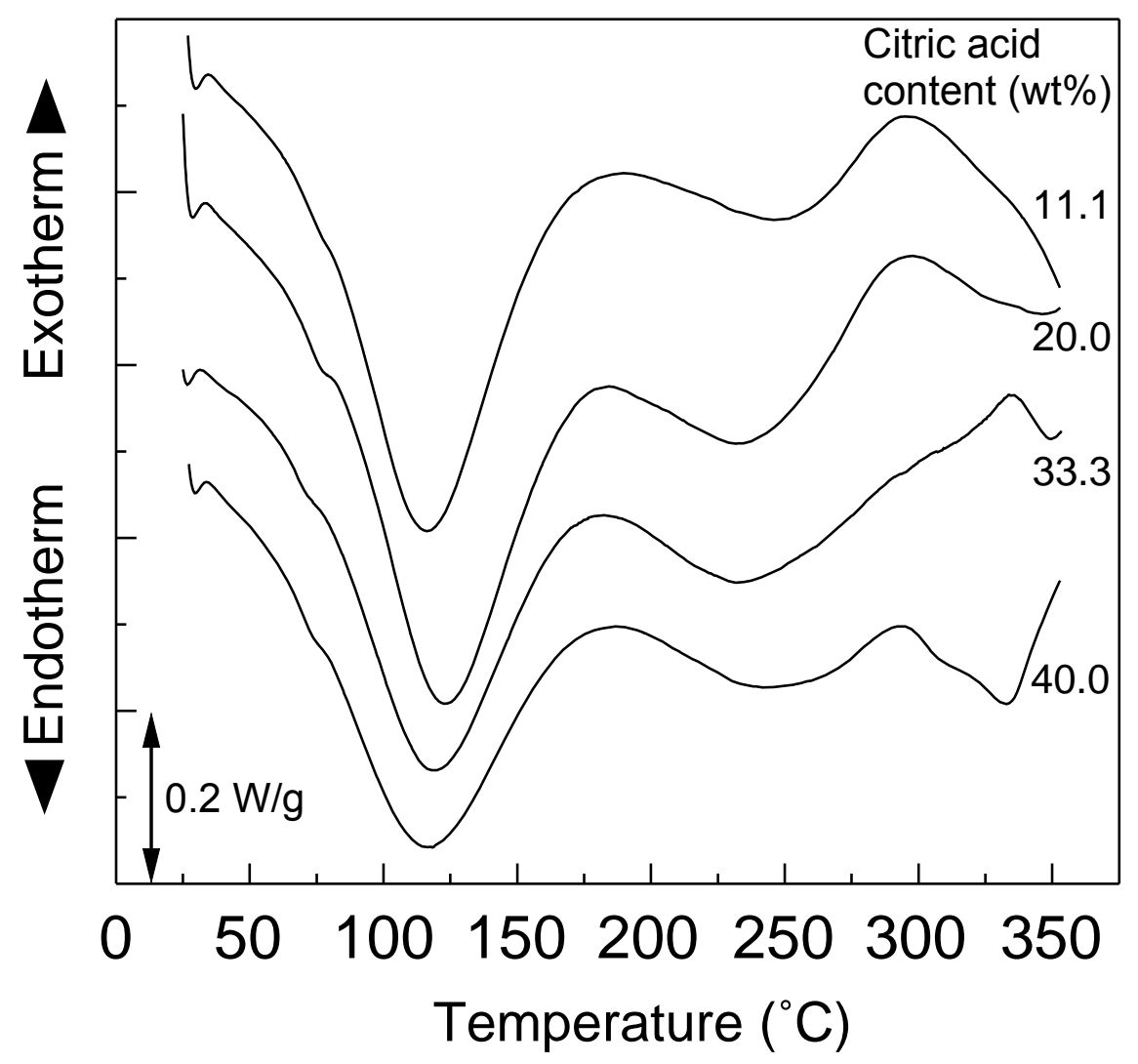

Fig. 10. 


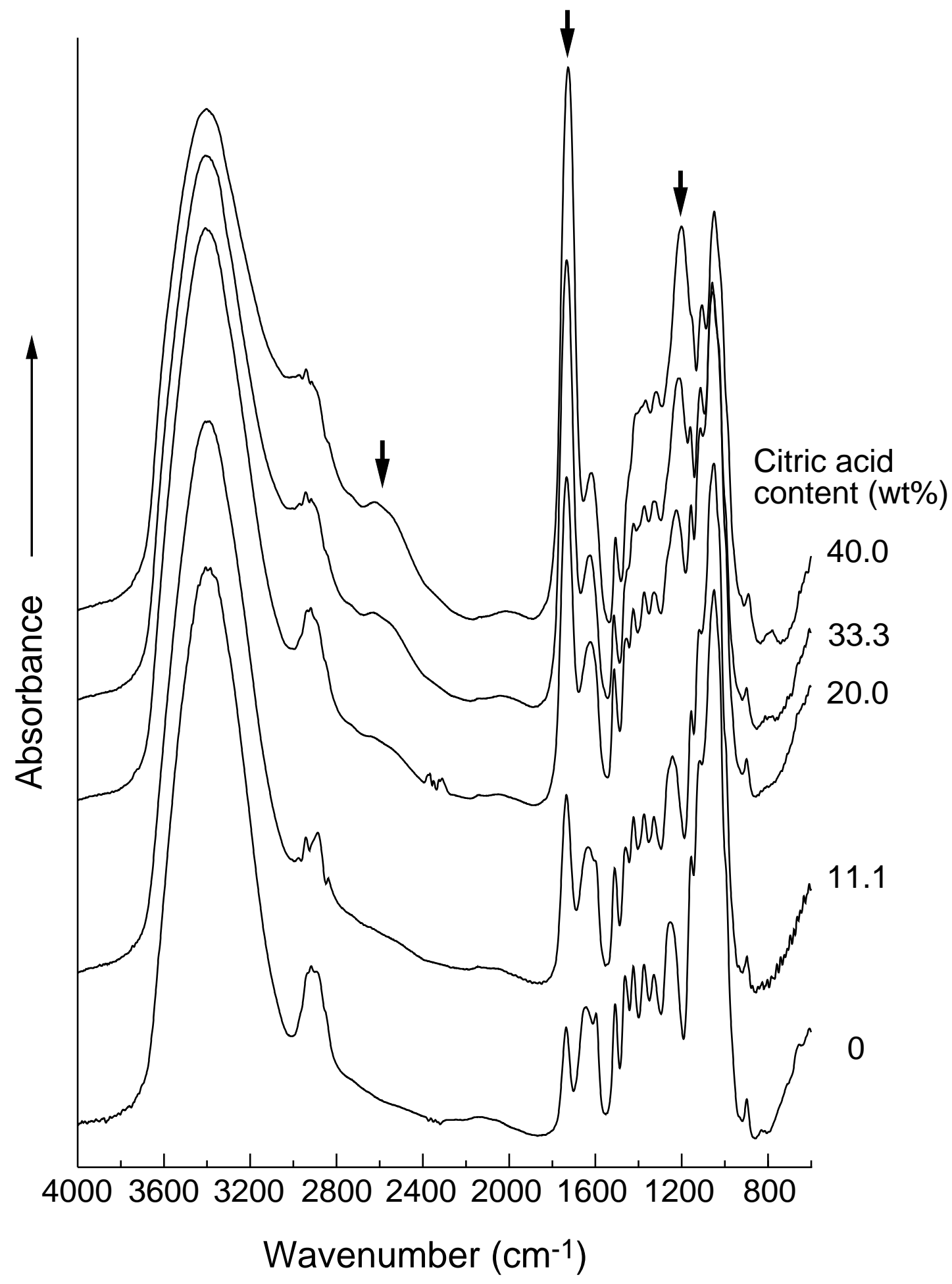

Fig. 11. 


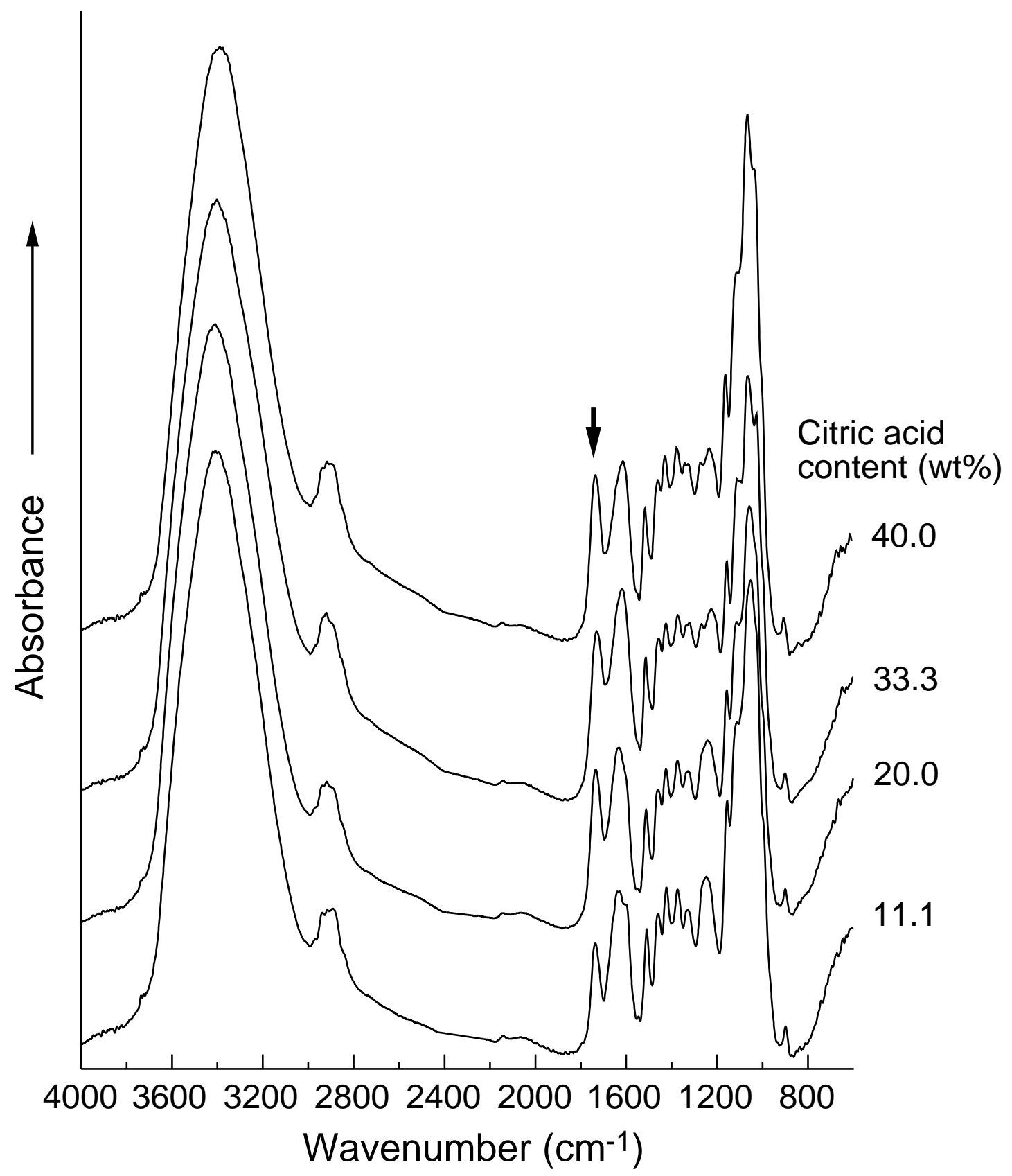

Fig. 12. 